REGARDS

SUR LEECONOMIE ALLEMANDE

BULLETIN ECONOMIQUE DU CRAC

\section{Regards sur l'économie allemande}

Bulletin économique du CIRAC

$80 \mid 2007$

Varia

\title{
Fret ferroviaire : une croissance de 8,0 \% en 2006
}

\section{Isabelle Bourgeois}

\section{OpenEdition}

\section{Journals}

Édition électronique

URL : http://journals.openedition.org/rea/712

DOI : $10.4000 /$ rea. 712

ISBN : 978-2-8218-0856-0

ISSN : 1965-0787

Éditeur

CIRAC

Édition imprimée

Date de publication : 1 mars 2007

Pagination : 38

ISSN : 1156-8992

Référence électronique

Isabelle Bourgeois, «Fret ferroviaire : une croissance de 8,0 \% en 2006 », Regards sur l'économie allemande [En ligne], 80 | mars 2007, document 3, mis en ligne le 01 mars 2009, consulté le 15 septembre 2020. URL : http://journals.openedition.org/rea/712

Ce document a été généré automatiquement le 15 septembre 2020

(C) CIRAC 


\title{
Fret ferroviaire : une croissance de $8,0 \%$ en 2006
}

\author{
Isabelle Bourgeois
}

1342,8 millions de tonnes de fret ont été transportées sur le réseau ferré allemand en 2006, soit 25,5 millions de tonnes de plus qu'en 2005. Cela représente une hausse de $+8,0 \%$, explique Destatis - la plus forte jamais enregistrée depuis l'Unité allemande. Cette croissance est pour une bonne partie imputable à l'intermodalité; le seul transport de conteneurs et autres unités de transport intermodal (57,1 millions de tonnes) a connu une hausse de $+13,6 \%$. Par ailleurs, pour la première fois, le nombre de tonnes-kilomètre a dépassé la barre des 100 milliards, atteignant 105,8 milliards $(+10,8 \%)$. Autre record: la distance moyenne parcourue par tonne était de $309 \mathrm{~km}$ $(+2,6 \%)$.

2 Reflet de l'ouverture de l'économie allemande et de la place centrale de l'Allemagne dans l'espace européen, c'est le transport transfrontières qui a enregistré la plus forte croissance. 54 millions de tonnes de fret $(+12 \%)$ ont été acheminées hors d'Allemagne ; avec un quart du total, l'Italie représente la principale destination. Sur les 55,8 millions de tonnes en provenance de l'étranger $(+9,1 \%)$, la plus grande partie (14,7 millions de tonnes) venait des Pays Bas. Si le trafic domestique pèse toujours le plus lourd avec 215,6 millions de tonnes, il n'a en comparaison augmenté que d'un 'maigre' $6,9 \%$. Tout à l'inverse du transit, qui a progressé de 7,6\% pour s'établir à 17,5 millions de tonnes.

Parmi les biens transportés, les produits issus de l'agriculture se taillent la part du lion en termes de croissance $(+26,5 \%)$, bien que leur tonnage soit relativement modeste (10,7 millions) en comparaison des métaux et ferrailles, catégorie la plus importante avec 58,8 millions de tonnes $(+15,6 \%)$. Elle est suivie des combustibles minéraux solides $(51,1$ millions de tonnes; $+3,1 \%)$. Les produits pétroliers ne viennent qu'en 4 ème position, avec 36,8 millions de tonnes; $+2,8 \%$ ). Toutes les catégories de biens sont en hausse, sauf celle des produits chimiques ( 24,9 millions de tonnes) qui enregistre une baisse de $-4,1 \%$. 
INDEX

Mots-clés : fret, marchandise, transport 